\title{
TEMPERATURE EFFECTS ON TURBINE BLADES SUBJECTED TO FATIGUE- CREEP INTERACTION LOAD
}

*Mohammed Mazin Khazaal ${ }^{1}$
Prof. Dr. Bashar Owaid B. ${ }^{1}$

1) Mustansiriyah University, College of Engineering, Mechanical Engineering Department, Baghdad, Iraq

\begin{abstract}
This work is devoted to study experimentally fatigue - creep interaction with temperature on low stage steam turbine blade for GE turbine blade in Baghdad south power plant. Prior to carry the test a chemical and tensile test are done to the blade to investigate some required properties such yield stress, elongations which will fed to the fatigue -creep interaction test. An electrical furnace was designed and used to enclose the blade specimen and adjusting and simulate the temperature in real which is ranged between $(50-250){ }^{\circ} \mathrm{C}$. a theoretical model is studied and suggested. The results show; Increasing temperature (up to $250^{\circ} \mathrm{C}$ ) will be causes a decrees in the mechanical properties by $(40.05 \%, 45.16 \%$ and $87.44 \%)$ in Ultimate tensile stress, Yield stress and Young's modules respectively. Also, Increasing temperature to $250^{\circ} \mathrm{C}$ will be causes a decrees in the endurance limit of the steam turbine blade by $87.82 \%$ (from 38 to $250^{\circ} \mathrm{C}$ ).
\end{abstract}

Keywords: Power plant, fatigue creep, interaction, turbine blade

\section{Introduction}

Now days power plants are considered as one of the main issues that affect human life directly. Electricity power is commonly generated using steam power plants. The plant output depends on the design of the steam plant, material used and mechanical treatments. The electric power stations have witnessed great developments after nuclear energy discovery. As power plants utilize heat of fusion of the nuclear cover this has led to turbines that work at higher heat and rotational speeds. This also leads to an increase in turbine stresses that very much limit blade life. Hence, this study deals creep fatigue interaction in turbine blade [1]. Turbine blades are the major important element in the turbine. They are the essential element that converts work fuel energy to kinetic energy [2]. TB is of two forms: fixed and moving blades. The fatigue is centralizing failure processes for components provided by cyclic-loading and unloading. It is results of the cumulative procedure consist of crack propagation, and final damage of ingredient. During cyclicloading; centralizing plastic deformation could take place in highest strengths [3]. Failures of most engineering components operating at elevated temperature under cyclic loading are caused by combined operations, including not fatigue only, but creep also and the action of offensive environment. These operations might be acting interactively or independently. Creep, which is a time dependent operation, depend on history of stresses and temperature which applied to the ingredients; where fatigue damage is produced by the cyclic stress and depend on

\footnotetext{
*Corresponding author: mohammadabunayla@yahoo.com
} 
time independent plastic strain. When the two damage ingredients acts in a combined manner, a creep fatigue interaction produced [4]. In order to explain the failure mechanism of creep fatigue; a list of tests to evaluate life of specimen subjected to such interaction will be considered in this thesis by alterative bending. (Suhas B, A R Anwar Khan, 2014) [5], investigated the LCF damage of LP steam turbine blade, The endurance limit of Disc and Blade have been more than $10^{4}$ cycle as founded by the analytical and theoretical analyses, therefore the disc and blade could be made by using in thermal power plants for over (20 years) without fatigue damage leading to turbine failure. The creep lives of the disc and blade have been obtained to be over (172800 hours). As a result the Disc and blade could perform effectively for over (20 years) without leading to creep damage. (E. Vacchieri et.al., 2017) [6] studded the flexibility increment that the energy market demands make the outstanding conditions of GT ingredients More and more critical time for reaction creep fatigue. A new living strategy was developed to estimate the life expectancy of the rotors and panels in this delicate state of service, taking into account the interaction of crawl and stress the transmitted observations submitted using the Weibull statistic were handled. Statistical treatment of the crack size of the critical place provides an assessment of crack initiation that has a good agreement with the living strategy. Moreover, the feedback that can be obtained on the first stage code allows the depth of the linear crack volume to be installed. This relationship was used to determine the maximum. The allowed crack length for safe operation of these components. (S.Naveen kumar1,2018) [7] studied finite element analysis using ANSYS software. Various types of loads operating on the blade of the steam turbine and the resulting developments have been studied in the blade.
The power of fatigue may be put on steam. maximum. Steam speed range (from cutting to steam speed) is needed for blade design as well as life expectancy for blade fatigue. When the load of $47730 \mathrm{~N}$ is applied on a turbine blade then the deformation and von misses stress will be obtained. The obtained maximum deformation is 0.108 max and von misses stress will be $1.229 \mathrm{e} 10$ (maximum) and the fatigue life cycle is be determined/predicted. Within this fatigue criterion our consideration blade is safe. (Esakki Muthu Shanmugam, Raghu V. Prakash, 2020) [8] the low cycle fatigue-creep damage is the main parameter for the failures of gas turbine components under high temperature and cyclic loading. In this work, different combinations of Creep-Fatigue damage are introduced and checked for its impact on the Turbine life and its reliability. Linear and NonLinear Creep-Fatigue combinations were considered as part of this work. The Turbine rotor under present study is made out of Nimonic-90 nickel base alloy forging. Weibull distribution method was used to study the reliability. It was found that, the reliability reduces from $99 \%$ to $25 \%$ when creep damage component is increased from $20 \%$ to $40 \%$ for a fixed Turbine life. The damage factor was found more in above linear Creep-Fatigue curve and less in below linear Creep-Fatigue curve.

\section{Experimental Work}

\subsection{Turbine Blades}

A sample of the turbine blade was taken for the tests that was carried out at the General Company for Engineering Inspection and Rehabilitation (used turbine blade). Steam turbine blade (that used in this work) specifications are: Turbine no. 197896 and turbine type it straight condensing single flow. Driving 73000 KVA, 11500 V. Hydrogen cooled generator $250 \mathrm{~V}$ static exciter. The 
thickness of the turbine blade was variable depending on its geometrical shape. Operating speed $3000 \mathrm{rpm}$. Steam condition operating is (initial pressure $850 \mathrm{psig}$, initial temperature 900FTT and back pressure 2.5 inches $\mathrm{Hg} \mathrm{Abs).}$

\subsection{Chemical Test}

The Department of Laboratories and Engineering Inspection for the purpose of knowing the components and metals used in the turbine alloy. Table (1) shows the chemical composition of the turbine blade that was used in this work.

\begin{tabular}{cccc}
\hline \multicolumn{4}{l}{ Table 1. Chemical Test } \\
\hline Sample & $\begin{array}{c}\text { Part of turbine } \\
\text { blade }\end{array}$ & Sample & $\begin{array}{c}\text { Part of turbine } \\
\text { blade }\end{array}$ \\
$\mathrm{C} \%$ & 0.15 & $\mathrm{Mo} \%$ & 0.0211 \\
$\mathrm{Si} \%$ & 0.412 & $\mathrm{Ni} \%$ & 0.218 \\
$\mathrm{Mn} \%$ & 0.581 & $\mathrm{~V} \%$ & 0.0592 \\
$\mathrm{P} \%$ & 0.0144 & $\mathrm{Cu} \%$ & 0.0942 \\
$\mathrm{Cr} \%$ & 12.6 & $\mathrm{Fe} \%$ & $\mathrm{Bal}$ \\
\hline
\end{tabular}

\subsection{Preparation of Specimens}

The preparations of specimens were done as follow;

1) There are many types of turbines. In this study, steam turbine blade will be operated according to specifications mentioned above.

2) A section of the turbine blade was taken and cut off by a wire cutting machine, see figure (1).

3) Cut the specimens for the tensile test according to ASTM E8/E8M-11 [9] with a $2 \mathrm{~mm}$ thickness, figure (2) and figure (3) show the tensile test specimen.
4) Cut the fatigue test specimens according to machine specification manual [10] with a $2 \mathrm{~mm}$ thickness, see figure (4) and figure (5).

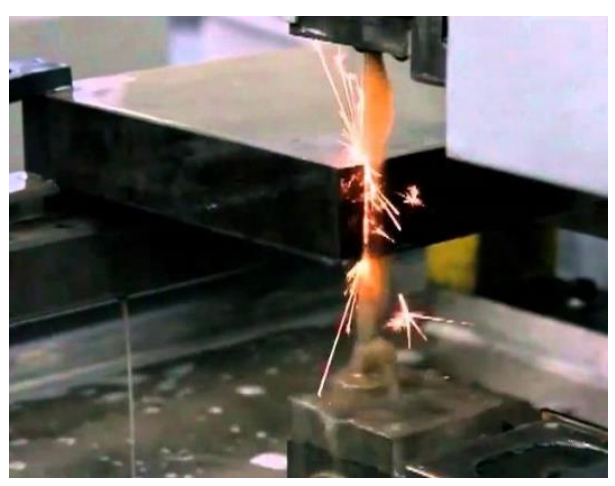

Figure 1. Wire Cutting Machine

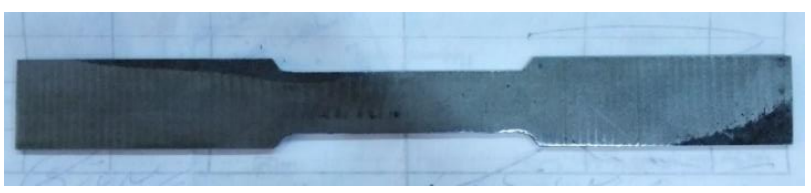

Figure 2. Tensile Test Specimen

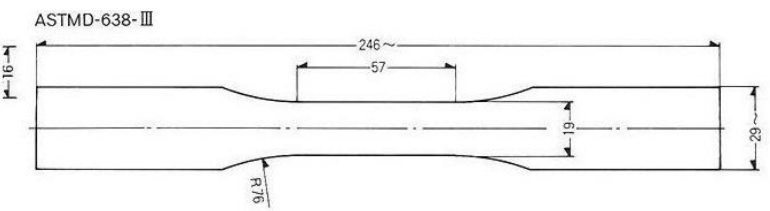

Figure 3. Graphical Diagram for Steam Turbine Blade Tensile Specimens According to ASTM E8/E8M-11 [all Dimensions in $\mathrm{mm}$ ] [9].

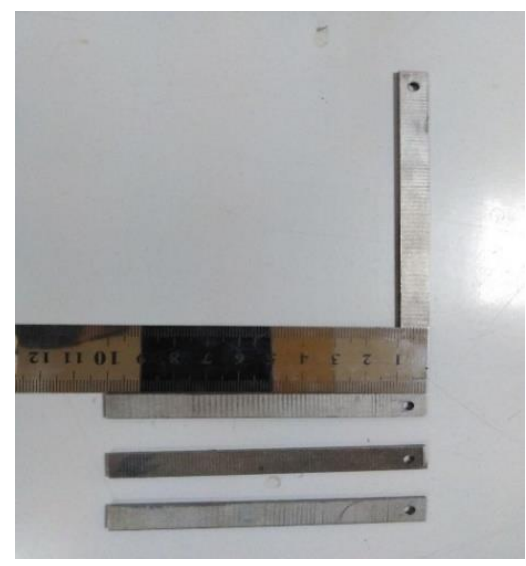

Figure 4. Fatigue Test Specimen. 


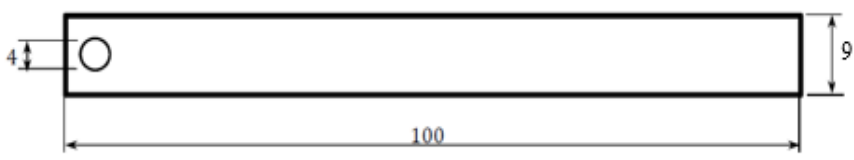

Figure 5. Graphical Diagram of Fatigue Test Specimen According to Specifications of Machine [Dimensions in $\mathrm{mm}][10]$.

\subsection{Tensile Test}

\subsubsection{Tensile Test without Temperature}

The tensile test machine was performed to measure the mechanical properties of the steam turbine blade. The tensile machine type is a micro-computer electronic testing machine WDW-100E, in which the test has been, achieved in General Company for Engineering Inspection and Rehabilitation (figure 6).

Tensile tests had been done for a many specimens at a different temperature by two specimens for every case and evaluate the average-value to satisfy further accurate results.

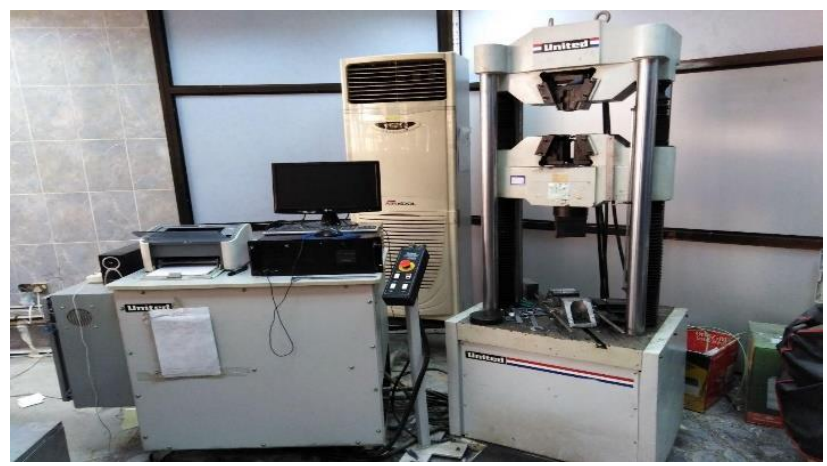

Figure 6. Tensile Testing Machine

\subsubsection{Tensile Test with Temperature}

This test was performed to measure the mechanical properties of the steam turbine blade to different values of temperatures (from 38 to $250{ }^{\circ} \mathrm{C}$ ). Figure (7) shows the special furnace for the tensile test to obtain the temperature condition

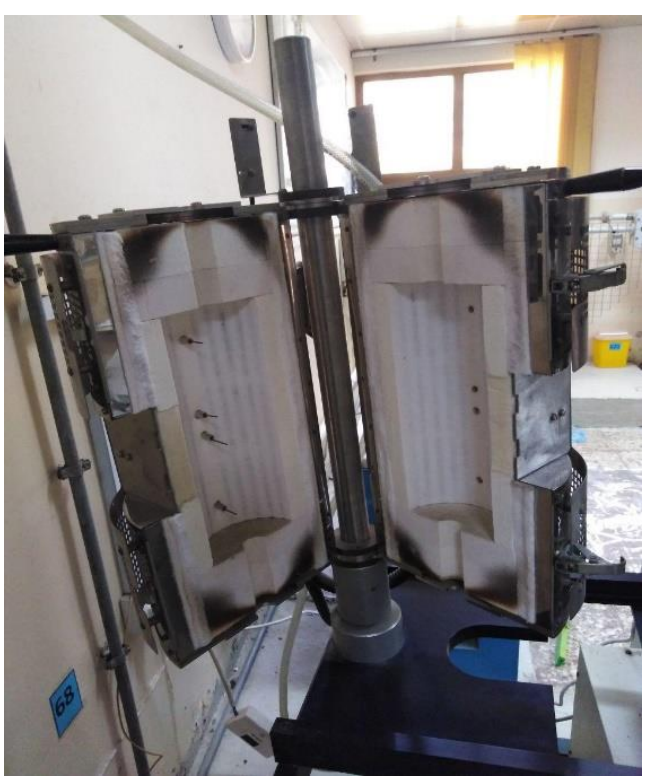

(a)

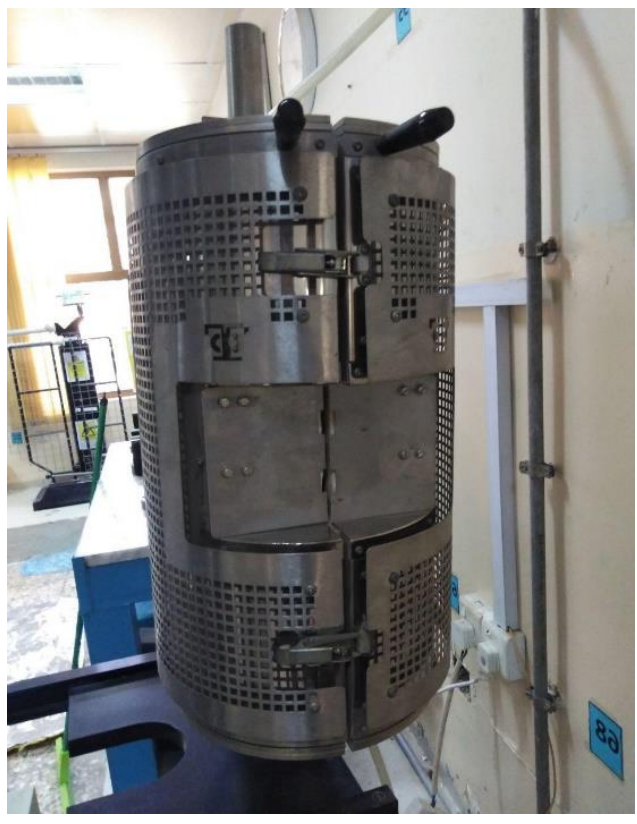

(b)

Figure 7. (a, b) Heat Furans of Tensile Testing Machine

\subsection{Fatigue Test}

\subsubsection{Fatigue Test without temperature}

The fatigue action of the steam turbine blade can be obtained from laboratory tests. HI-TECH alternating bending fatigue (HSM20) was the fatigue testing machine used in this work with a constant amplitude, where the tests were accomplished in Materials Engineering Department in ALMustansiriyah University College of Engineering (fig. 8). 


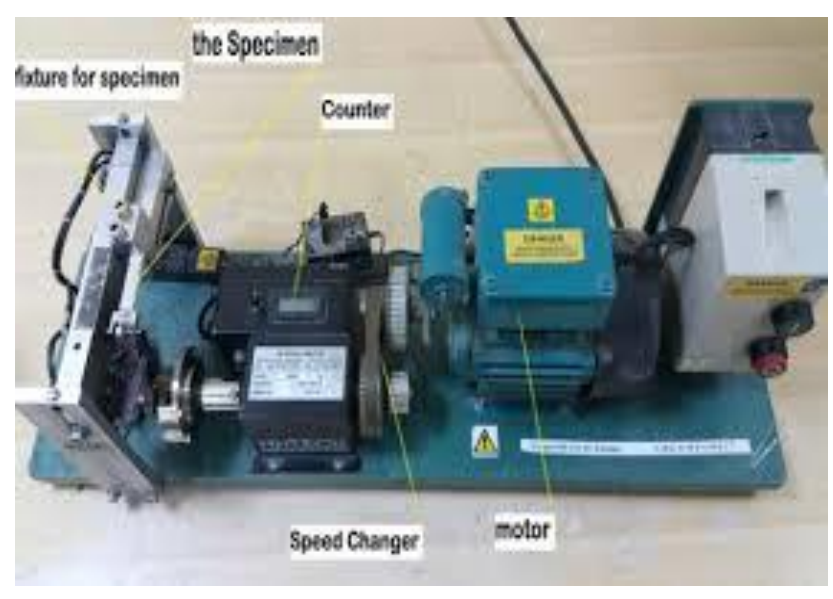

Figure 8. Fatigue Testing Machine

\subsubsection{Fatigue Test with temperature}

The stress-stress testing machine used in this work was a device that matched the abovementioned fatigue device with the addition of a furnace was designed especially for this work, it includes a cast iron container of two pieces to cover the fatigue specimen in the fatigue device to obtain a constant temperature around the test specimen with a heater (and an SSU thermostat controller $\left(0-300^{\circ} \mathrm{C}\right)$ placed at the top side of the container as shown in figures (9 and 10).

The attached heater capacity is connected to 4000 watts combined with a heat regulator to obtain the required temperature inside the container. The range of thermostat ranges from (0 to $300^{\circ} \mathrm{C}$ ).

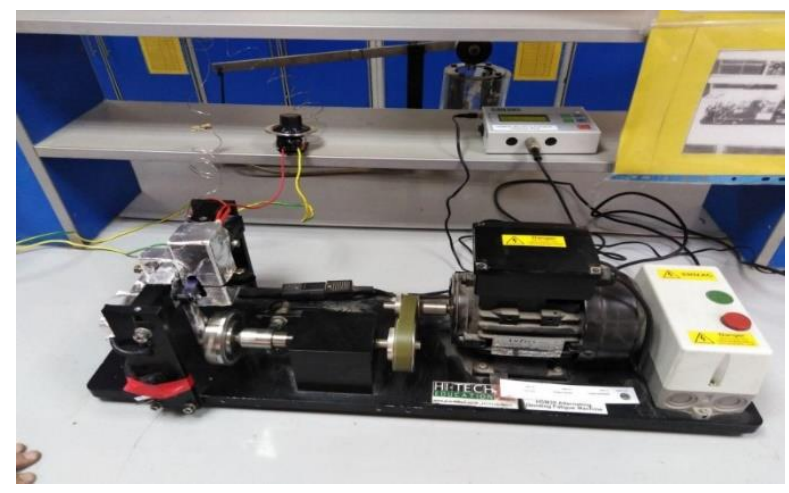

(a)

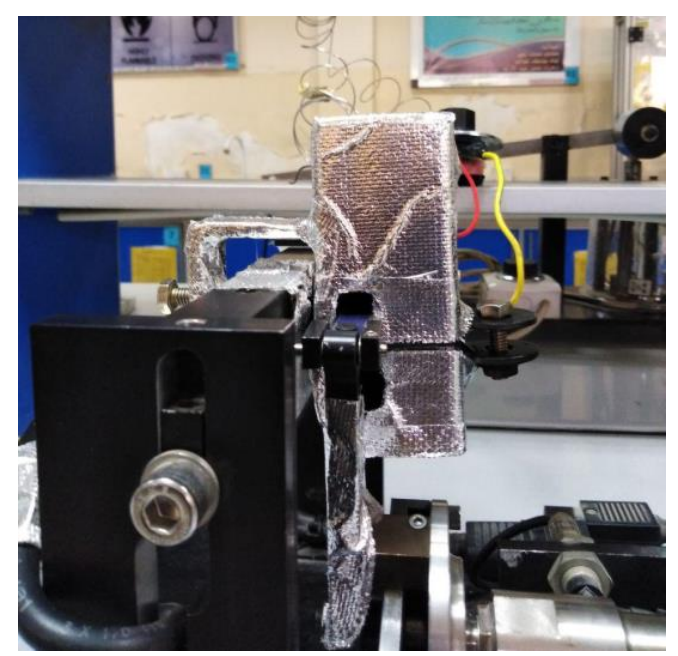

(b)

Figure 9. (a, b) Fatigue Testing Machine with the Furnace.

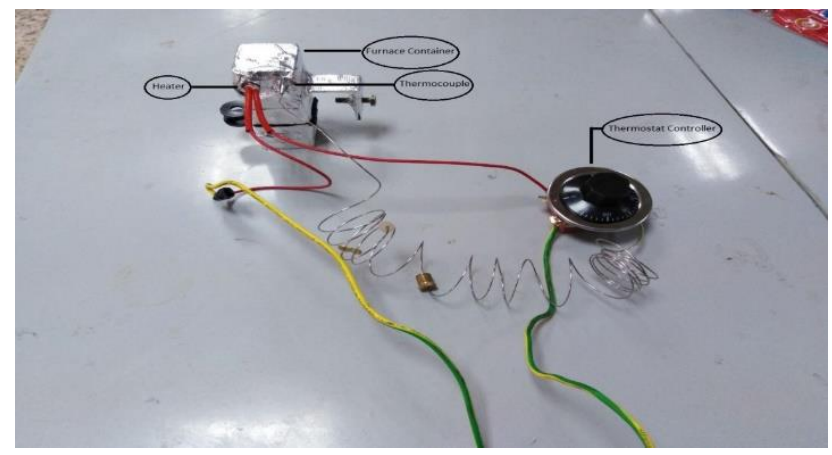

Figure 10. Furnace Circuit Parts.

\section{Numerical Verification}

One of the most powerful numerical procedures is the Finite Element Method (FEM) which may be used to get the solutions of a large number of engineering problems, particularly in the area of solid mechanics. In this research, FEM by the help of Analysis Systems ANSYS.15 program was utilized as the numeric tool for obtaining the effect of Fatigue Creep Interaction on the Turbine Blades. The major reason for using a FEM analyses was to simulate numerically how the real engineering system will behave.

\subsection{Constructing the Model}

For building a finite element model, many steps should be made: First of all, specifying the work's title and analysis should be done, after that, defining the material properties, and the 
geometry of the model. The dimensions of the current model are $[50 \times 9 \times 2]$; all dimensions are in $(\mathrm{mm})$.

\subsection{Creating the Mesh for Model}

This process (meshing) was done by selecting the part that needed to be meshed and selecting the meshing option, see figure (11). Total elements' number in this work was 960 elements with 5335 nodes, the element type is that element which has 20 nodes. The mesh size could be changed to satisfy the needed number of nodes and elements.

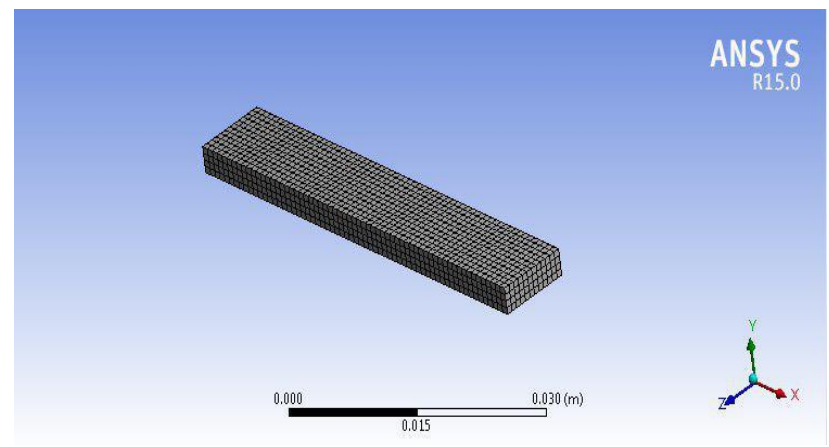

Figure 11. The Model with Mesh.

\section{Results and Discussion}

\subsection{Tensile Test Results}

This test was carried out for the purpose of obtaining the mechanical specifications required in this study see table (2). The ultimate tensile strength, yield tensile stress and modulus of elasticity for steam turbine blade have been gained from the tensile test.

From the table (2), it can be seen, the decreases in Modulus of Elasticity and Ultimate Tensile Stress and yield stress. The reason for this decrease is increasing in temperature degree. Figure (12) shows a comparison between ultimate stress and the yield stress, also there affect to increasing temperature.
Table 2. the Mechanical Properties Obtained from the Tensile Test for the Steam Turbine Blade

\begin{tabular}{cccc}
\hline $\begin{array}{c}\text { Temperature } \\
\left({ }^{\circ} \mathbf{C}\right)\end{array}$ & $\begin{array}{c}\text { Ultimate } \\
\text { stress } \\
(\mathrm{MPa})\end{array}$ & $\begin{array}{c}\text { Yield } \\
\text { strength } \\
(\mathrm{MPa})\end{array}$ & $\begin{array}{c}\text { Young's } \\
\text { models } \\
(\mathrm{GPa})\end{array}$ \\
R.T(38) & 669 & 600 & 11.15 \\
50 & 669 & 600 & 11.15 \\
75 & 655 & 596 & 11 \\
100 & 644 & 582 & 10.7 \\
125 & 590 & 550 & 9.6 \\
150 & 568 & 518 & 8.11 \\
175 & 537 & 473 & 6.88 \\
200 & 481 & 420 & 4.48 \\
225 & 448 & 375 & 2.8 \\
250 & 401 & 329 & 1.4 \\
\hline
\end{tabular}

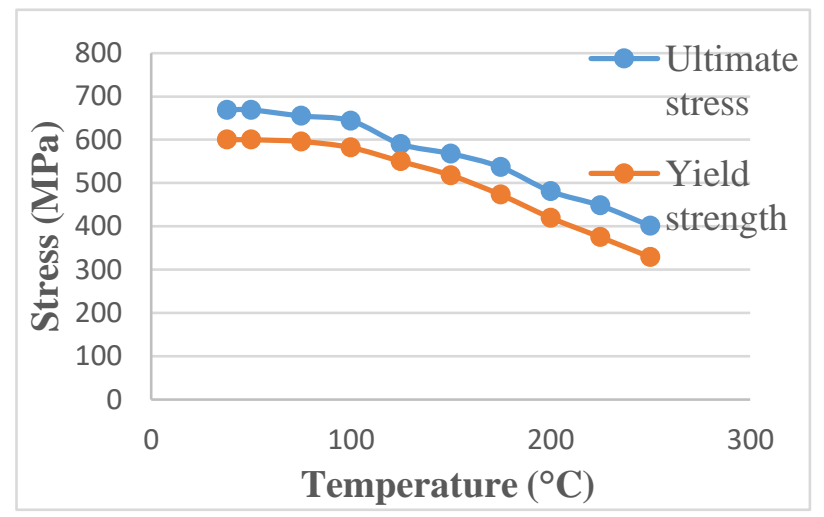

Figure 12. Comparing the effect of temperature between Ultimate stress and Yield stress

\subsection{Fatigue Testing Results}

The fatigue test was done in a (R.T (38), 75, $100,125,150,175,200,225$ and 250) $\mathrm{C}^{\circ}$ and it's behavior is explained as fatigue strength with numbers of cycle to failure curve ( $\mathrm{S}$ $\mathrm{N})$ curve, see figures (13 and 14)

Equation for defining these curves is the power law equation (equation 1) and the equations of S-N curve for all cases are listed in Tables (3).

$\sigma_{\mathrm{a}}=\mathrm{A} * \mathrm{~N}^{-\mathrm{B}}$ basquin equation [11] 
Where

бa: fatigue strength (MPa).

$\mathrm{N}$ : numbers of cycles to fail (cycle).

$\mathrm{A}$ and $\mathrm{B}$ constant depends on the material.

From these two figures (13 and 14), The S-N curve obtained for the steam turbine blade at room temperature shows that the endurance limit equals 27.6 Mpa. Increasing temperature will be causes a decrees in the endurance limit of the steam turbine blade. Increasing temperature from room temperature to $250^{\circ} \mathrm{C}$ will be causes a $87.82 \%$ decrees in the endurance limit.

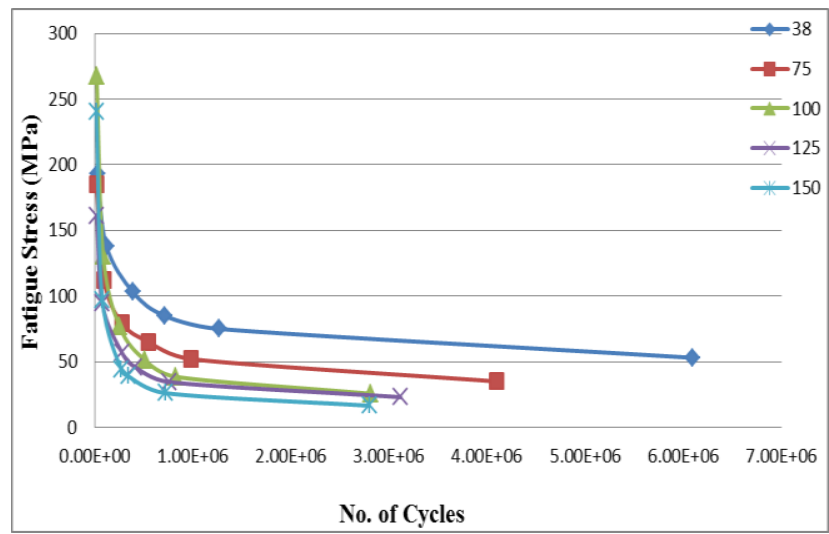

Figure 13. S-N Curve for the Steam Turbine Blade used in this Work at Different Temperatures (38, 75, $100,125$ and 150$){ }^{\circ} \mathrm{C}$

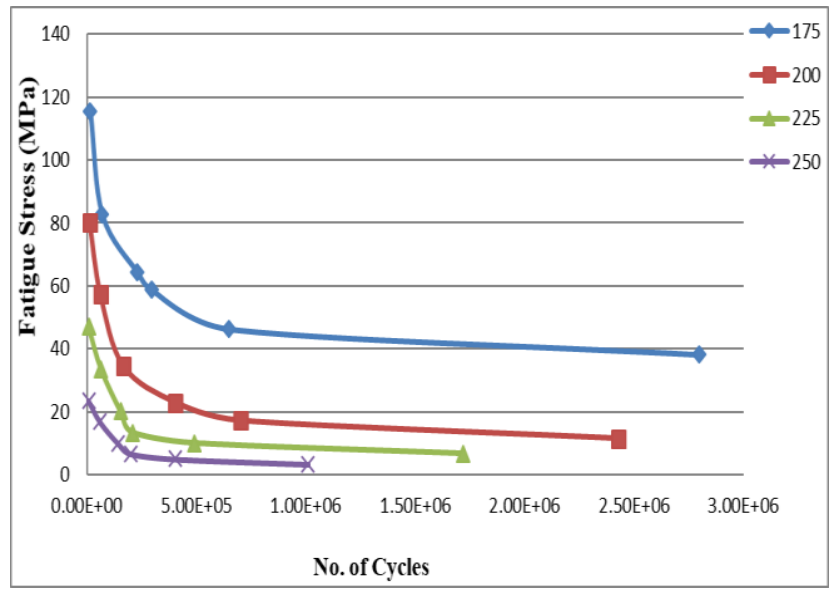

Figure 14. S-N Curve for the Steam Turbine Blade used in this Work at Different Temperatures (175, 200, 225 and 250$){ }^{\circ} \mathrm{C}$
From two figures above can be seen that the temperature affects the endurance limit of turbine blades.

These two figures show that the endurance limit for the turbine blades Equal to (27.6) $\mathrm{MPa}$ at $38^{\circ} \mathrm{C}$, and this value decreases by $4.34 \%$ when the temperature increase to 75 , and decreases by $7.42 \%, 16.52 \%, 24.47 \%, 40.17 \%, 58.43 \%$, $75.65 \%$ and $87.82 \%$ for $100,125,150,175$, 200,225 and $250{ }^{\circ} \mathrm{C}$ respectively.

\subsection{Numerical Results}

The most important parameter that can be inferred from the numerical analysis is the fatigue life. The comparison between experimental S-N curve results and numerical S$\mathrm{N}$ curve results was done after determining the fatigue life estimation for each case (experimental or numerical) using the power law equation (equation 1) (mentioned above) and they are listed in Table (3) for all cases of the steam turbine blade. In this table, the percentage of difference of fatigue stress between the experimental work and the numerical work is also listed, and it is calculated using (equation 2);

Percentage Error $=\frac{\sigma \max -\sigma \min }{\sigma \max } \mathrm{X} \quad 100 \%$

Table (3) displays that the max. Percentage change between the experimental and numerical values of endurance limit for the woven reinforced composite material does not exceed $7.13 \%$. 
Table 3. Experimental and Numerical Equations of S-N Curves for all Cases of Steam Turbine Blade at different temperature with the Percentage change between Experimental and Numerical endurance limit Result

\begin{tabular}{|c|c|c|c|}
\hline $\begin{array}{c}\text { Temperature } \\
\left({ }^{\circ} \mathbf{C}\right)\end{array}$ & $\begin{array}{c}\text { Experimental } \\
\text { S-N curve } \\
\text { equation }\end{array}$ & $\begin{array}{l}\text { Numerical } \\
\text { S-N curve } \\
\text { equation }\end{array}$ & $\begin{array}{l}\text { Percentage } \\
\text { Difference }\end{array}$ \\
\hline R.T(38) & $\begin{array}{c}\sigma=2526.7 * \\
\mathrm{~N}^{-0.2486}\end{array}$ & $\begin{array}{c}\sigma=2841.16 * \\
\mathrm{~N}^{-0.2646}\end{array}$ & 2.74 \\
\hline 75 & $\begin{array}{c}\sigma=4151.34 \\
* \mathrm{~N}^{-0.31586}\end{array}$ & $\begin{array}{c}\sigma=4631.78^{*} \\
\mathrm{~N}^{-0.3234}\end{array}$ & 3.8 \\
\hline 100 & $\begin{array}{c}\sigma=46440.6 * \\
\mathrm{~N}^{-0.518}\end{array}$ & $\begin{array}{c}\sigma=38939 * \\
\mathrm{~N}^{-0.5046}\end{array}$ & 5.1 \\
\hline 125 & $\begin{array}{c}\sigma=9939 * \mathrm{~N}^{-} \\
0.4155\end{array}$ & $\begin{array}{c}\sigma=8141.2 * \\
\mathrm{~N}^{-0.399}\end{array}$ & 4.63 \\
\hline 150 & $\begin{array}{c}\sigma=98444 * \\
\mathrm{~N}^{-0.6164}\end{array}$ & $\begin{array}{c}\sigma=69434 * \\
\mathrm{~N}^{-0.5853}\end{array}$ & 6.07 \\
\hline 175 & $\begin{array}{c}\sigma=839.74 * \\
\mathrm{~N}^{-0.2082}\end{array}$ & $\begin{array}{c}\sigma=687.24 * \\
\mathrm{~N}^{-0.1898}\end{array}$ & 3.04 \\
\hline 200 & $\begin{array}{c}\sigma=563.7 * \\
\mathrm{~N}^{-0.2073}\end{array}$ & $\begin{array}{c}\sigma=388.03 * \\
\mathrm{~N}^{-0.1722}\end{array}$ & 4.89 \\
\hline 225 & $\begin{array}{c}\sigma=652.2 * \\
\mathrm{~N}^{-0.291}\end{array}$ & $\begin{array}{c}\sigma=817.6 * \\
\mathrm{~N}^{-0.314}\end{array}$ & 1.6 \\
\hline 250 & $\begin{array}{c}\sigma=126.6 * \\
\mathrm{~N}^{-0.186}\end{array}$ & $\begin{array}{c}\sigma=114.5 * \\
\mathrm{~N}^{-0.1746}\end{array}$ & 7.13 \\
\hline
\end{tabular}

\section{Conclusions}

The main conclusions from this work for steam turbine blades studies may be summarized as:

1-from the tensile test, the mechanical properties (Yield tensile stress, Ultimate stress and modules of elasticity) of the steam turbine blades at room temperature is; oult $=669 \mathrm{Mpa}, \sigma \mathrm{y}=600 \mathrm{Mpa}$ and $\mathrm{E}=11.15 \mathrm{GPa}$.

2-Increasing temperature will be causes a decrees in the mechanical properties by $(40.05 \%, 45.16 \%$ and $87.44 \%)$ in Yield tensile stress, Ultimate stress and modules of elasticity respectively.

3-Increasing temperature will be causes a decrees in the endurance limit of the steam turbine blade.

4-The numerical verification was done using ANSIS $\backslash$ Workbench.15 to obtain the S-N curves for the steam turbine blade. From the comparison, it can be seen that the maximum percentage difference between the experimental and numerical values of the $S$ $\mathrm{N}$ curves for the steam turbine blades at a different temperature does not exceed $7.13 \%$.

\section{Conflict of interest}

The authors confirm that the publication of this article cause no conflict of interest.

\section{References}

1. Kearton W.J., (1990). "Steam Turbine Theory and practice", 8 Edt, wiley-interscience publication (J W S' S).

2. John F.Lee., (1954). "Theory and Design of Steam and Gas Turbine", McGraw-Hill, Book Company, Inc.

3. Yung-Li Lee, Jwo Pan, Richard B. Hathaway and Mark E.Barkey, (2005). "Fatigue science book testing and analysis Theory and Practice Copyright Elsevier Inc.

4. ASM handbook, (1996). "Fatigue and Fracture", vol.19, material park, Ohio, ASM international, page 1257.

5. Suhas B, Anwar Khan, (2014). "Fatigue and Creep Interaction in Steam Turbine Bladed Disk", International Journal of Innovative Research in Science, Engineering and Technology Vol. 3, Issue 6. 
6. M. Beghinia, L. Bertinia, C. Santusa, B.D. Monellia, E. Scrinzib, N. Pieronib, I. Giovannettib, (2017) "High temperature fatigue testing of gas turbine blades" $3 \mathrm{rd}$ International Symposium on Fatigue Design and Material Defects, FDMD 2017, 19-22, September, Lecco, Italy

7. S.Naveen kumar1, Konduru Sivaprasad Raju2 , S.Bhakiyaraja3 , Dr.D .Vijayaganapathy4, (2018) "Static And Designe Analysis Of A Steam Turbine Blade", International Journal of Pure and Applied Mathematics Volume 120 No. 6,pp 3989-3996.

8. Esakki Muthu Shanmugam and Raghu V. Prakash, (2020). "The Effect of CreepFatigue Interactions on Thermo-Mechanical Fatigue Life and Reliability Estimates for a Typical Gas Turbine Engine Component", ASME international mechanical engineering congress and exposition, Volume 12.

9. American Society for Testing and Materials (ASTM) E8/E8M-11, (2001). Annual book of ASTM standards.

10. N. P. Roberts and Nigel R. Hart, (2001). "Alternating Bending Fatigue Machine (HSM20), Instruction Manual", Hi-Tech Ltd. UK.

11. N.Ahmed Al-Khazraji, (2014). "Effect of Shot Peening on Mechanical Properties and Endurance Limit of Composite Materials", M.Sc. Thesis, Mechanical Engineering Department, University of Technology, 2014. 